\title{
FONTES ENERGÉTICAS ASSOCIADAS AO FARELO DE GIRASSOL OU À UREIA EM DIETAS PARA NOVILHOS
}

\author{
ENERGY SOURCES ASSOCIATED TO SUNFLOWER MEAL OR UREA IN STEERS DIETS \\ Van Cleef, E.H.C.B. ${ }^{1 *}$, Ezequiel, J.M.B. ${ }^{2}$, Gonçalves, J.S. ${ }^{3}$, Fontes, N.A. ${ }^{2}$, \\ Oliveira, P.S.N. ${ }^{4}$ e Stiaque, M.G. ${ }^{2}$
}

\begin{abstract}
${ }^{1}$ Kansas State University. Manhattan-Kansas. Estados Unidos da América. *ericvancleef@gmail.com ${ }^{2}$ Faculdade de Ciências Agrárias e Veterinárias. Unesp. Campus de Jaboticabal-São Paulo. Brasil. ${ }^{3}$ Departamento de Ciências Animais. Universidade Federal Rural do Semi-Árido (UFERSA). Mossoró-Rio Grande do Norte. Brasil.

${ }^{4}$ Universidade Federal de São Carlos (UFSCAR). São Carlos-São Paulo. Brasil.
\end{abstract}

\section{PaLAVRAS ChaVe ADICIONAIS}

Co-produtos. Fontes energéticas. Fontes proteicas. Ganho em peso.

\section{RESUMO}

Objetivou-se avaliar o desempenho e as características da carcaça de novilhos alimentados com milho ou polpa cítrica associados ao farelo de girassol ou ureia. As dietas foram constituídas por duas fontes energéticas (grão de milho e polpa cítrica) associadas a duas fontes proteicas (farelo de girassol e ureia), totalizando quatro tratamentos, numa proporção volumoso:concentrado de 40:60. Foram utilizados 24 novilhos, $1 / 2$ Aberdeen Angus $\times 1 / 2$ Nelore (18 meses de idade e peso médio de $329 \mathrm{~kg}$ ), distribuídos em um delineamento inteiramente casualizado, terminados em confinamento por 80 dias. Foram avaliados consumos, ganho de peso e características da carcaça dos animais. Consumo de matéria seca (CMS), proteína bruta (CPB) e fibra em detergente neutro $(C F D N)$ foram influenciados $(p<0,05)$ pelas dietas experimentais. A dieta polpa cítrica e ureia (PU) apresentou os menores $(p<0,05)$ CMS $(8,30 \mathrm{~kg})$, CPB $(1,03 \mathrm{~kg})$ e CFDN $(3,31 \mathrm{~kg})$. O ganho de peso médio diário acompanhou o comportamento de CMS, CPB e CFDN e o menor valor $(p<0,05)$ foi observado nos animais da dieta PU. Nas características de carcaça, as dietas com milho associado à ureia (MU) ou ao farelo de girassol (MFG) e polpa cítrica associada ao farelo de girassol (PFG) mostraram altos $(p<0,05)$ pesos de carcaça fria $(238,37 ; 247,26$ e $237,14 \mathrm{~kg}$, respectivamente).

\section{AdDitional KeYWORDS}

Co-products. Energetic sources. Protein sources. Weight gain.

Porém, o menor rendimento de carcaça fria $(p<0,05)$ foi encontrado na dieta $\mathrm{MU}(50,57 \%)$. A associação polpa cítrica e ureia deve ser evitada quando a polpa cítrica substituir o milho como fonte energética, pois possivelmente promove um déficit energético, resultando em baixo desempenho e piores características de carcaça de novilhos terminados em confinamento.

\section{SUMMARY}

The objective of this study was to evaluate the performance and carcass traits of steers fed corn or citrus pulp associated with sunflower meal or urea. Diets were composed of two energy sources (corn grain and citrus pulp) associated with two protein sources (soybean meal and urea), resulting in four treatments in forage:concentrate ratio of 40:60. It were used 24 steers, $1 / 2$ Angus $\times 1 / 2$ Nellore (18 months old and $329 \mathrm{~kg} \mathrm{BW}$ ) distributed in a completely randomized design which were finished in feedlot for 80 days. It were evaluated the intake, average daily gain and carcass traits of the animals. Intake of dry matter (DMI), crude protein $(\mathrm{CPI})$ and neutral detergent fiber (NDFI) were affected $(p<0.05)$ by diets. The diet with citrus pulp and urea (PU) showed the lowest $(p<0.05)$ DMI $(8.30 \mathrm{~kg}), \mathrm{CPI}(1.03 \mathrm{~kg})$ and NDFI $(3.31$ 
$\mathrm{kg})$. The average daily weight gain (ADG) followed the behavior of DMI, NDFI and CPI and the lowest value $(p<0.05)$ was observed for animals fed diet PU. Regarding carcass traits, diets containing corn associated with urea (MU) or sunflower meal (MFG) and citrus pulp associated with sunflower meal (PFG), provided the highest $(p<0.05)$ carcass cold weights $(238.37,247.26$ and $237.14 \mathrm{~kg}$, respectively). However, the lowest cold carcass dressing percentage $(p<0.05)$ was obtained in diet MU (50.57\%). The association of citrus pulp with urea should not be performed when citrus pulp partially or totally replace corn as energy source in diets, because possibly this association promote an energy deficit resulting in lower performance and worse carcass traits of animals finished in feedlot.

\section{INTRODUÇÃO}

Embora o sistema de terminação em confinamento para bovinos proporcione ganhos de peso mais rápido quando comparado a terminação em sistemas extensivos, maior oferta de carne na entressafra, redução na idade de abate, liberação da área de pastagem para outras categorias animais, retorno do capital mais rápido e o aproveitamento de co-produtos oriundos da agroindústria, estimam-se que somente 2,7 milhões dos 41,2 milhões de bovinos abatidos por ano no Brasil sejam oriundos de terminação em confinamento (ANUALPEC, 2011).

O desempenho de animais em confinamento utilizando nas dietas co-produtos está diretamente relacionado à genética, tipo, quantidade e qualidade dos nutrientes presentes nos alimentos da dieta (Lema, 2001). Alguns co-produtos, como a polpa cítrica, são usados para substituir o milho ou a soja da dieta de ruminantes, que são ingredientes caros decorrente da alta demanda (Ferreira et al., 1999).

A polpa cítrica é um co-produto constituído de casca, sementes, bagaço e frutas cítricas descartadas que vem sendo amplamente utilizada por apresentar boa efetividade da fração fibrosa e elevada degradabilidade ruminal devido à presença de carboidratos solúveis (Carvalho, 1995; Santos et al., 2004), sem comprometer o consumo de matéria seca (Henrique et al., 1998) e ganho de peso (Prado et al., 2000).

A casca de soja, um co-produto resultante da descorticação do grão de soja, contribui para o aumento de fibra da dieta de ruminantes que recebem grandes quantidades de concentrado, de forma a minimizar os riscos de acidose ruminal (Galati, 2004; Ipharraguerre e Clark, 2003).

O farelo de girassol é outro co-produto da agroindústria, que possui concentração elevada de proteína bruta e pode ser um potencial substituto do farelo de soja. Já a ureia é uma das mais comuns fontes de nitrogênio não proteico em dietas de terminação de bovinos, sendo fonte de proteína degradável no rúmen e fornecendo nitrogênio para os microorganismos ruminais (Cooper et al., 2002). Porém, sua inclusão deve ser moderada devido à baixa palatabilidade (Kertz, 2010) e toxicidade (Haliburton e Morgan, 1989).

Objetivou-se neste trabalho avaliar o desempenho e as características de carcaças de novilhos confinados, alimentados com milho, casca de soja e polpa cítrica, associados ao farelo de girassol ou ureia como fontes nitrogenadas.

\section{MATERIAL E MÉTODOS}

O experimento foi conduzido no Setor de Confinamento do Departamento de Zootecnia da Faculdade de Ciências Agrárias e Veterinárias, Unesp - Câmpus de Jaboticabal, estado de São Paulo, Brasil.

Foram utilizados 24 novilhos de corte ( $1 / 2$ Aberdeen Angus $\times 1 / 2$ Nelore), com 18 meses de idade e $329 \mathrm{~kg}$ de peso médio inicial, os quais foram distribuídos em um delineamento inteiramente casualizado, com quatro tratamentos e seis repetições. Os animais foram confinados em baias individuais (14 $\mathrm{m}^{2}$ ) pavimentadas e parcialmente cobertas.

Quatro dietas foram formuladas com $40 \%$ de silagem de milho como volumoso e $60 \%$ 


\section{NOVILHOS CONFINADOS COM FONTES DE PROTEÍNA E ENERGIA}

de concentrado, sendo este composto por milho, polpa cítrica e casca de soja como fontes energéticas, associadas ao farelo de girassol ou ureia como fontes nitrogenadas. As dietas foram formuladas de acordo com as exigências do NRC (1996), visando um ganho diário de $1,4 \mathrm{~kg}$. A composição química dos ingredientes da dieta é apresentada na tabela I, enquanto a composição percentual e nutricional das dietas experimentais são apresentadas na tabela II.

Os alimentos foram fornecidos em duas refeições diárias, uma às oito e outra às 16 horas. O concentrado e a silagem foram misturados no comedouro no momento da alimentação. Diariamente, antes do fornecimento da manhã, as sobras de alimento foram colhidas e pesadas para ajuste de consumo. A oferta de alimento foi ajustada para que houvesse sobra de $5 \%$ do total fornecido.

O período experimental foi de 94 dias, dos quais os primeiros 14 dias foram destinados à adaptação dos animais à dieta $\mathrm{e}$ uniformização do consumo e os demais 80 dias, para fornecimento das dietas experimentais e colheita de dados.

Semanalmente amostras dos ingredientes das dietas e das sobras de cada animal foram coletadas e armazenadas para posteriores análises. Estas amostras foram então homogeneizadas em amostras compostas e enviadas ao Laboratório de Ingredientes e Gases Poluentes pertencente à Unidade Animal de Estudos Digestivos e Metabólicos vinculada ao Departamento de Zootecnia da Faculdade de Ciências Agrárias e Veterinárias, Unesp - Câmpus de Jaboticabal para a realização das análises laboratoriais. As amostras de silagem de milho, dieta e sobras foram pré secas em estufa com circulação forçada de ar regulada à temperatura de $55^{\circ} \mathrm{C}$ e posteriormente moídas em moinho tipo Willey em peneira com perfurações de $1 \mathrm{~mm}$. As demais amostras foram apenas moídas sob as mesmas condições acima descritas. Foram determinados os teores de matéria seca e proteína bruta pelo método Kjeldahl (AOAC, 1995) e fibra em detergente neutro (FDN), conforme Silva e Queiroz(2005).

Os animais foram pesados no início e no final do período de adaptação, e no final do período experimental, após jejum de alimento sólido de 16 horas, para a avaliação do ganho de peso total e ganho em peso médio diário; conversão alimentar e escore corporal. Este último foi avaliado atribuindo, aos

Tabela I. Composição dos ingredientes utilizados na formulação das dietas. (Composition of ingredients used on diets formulation).

\begin{tabular}{lccccc}
\hline Ítem & Silagem de milho & Milho em grão & Polpa cítrica & Casca de soja & Farelo de girassol \\
\hline MS (\%) & 36,58 & 85,56 & 85,11 & 90,18 & 90,24 \\
MO (\% MS) & 96,23 & 98,50 & 92,37 & 94,60 & 95,36 \\
Cinzas (\% MS) & 3,77 & 1,50 & 7,63 & 5,40 & 4,64 \\
PB (\% MS) & 7,95 & 10,60 & 8,27 & 11,31 & 32,50 \\
FDN (\% MS) & 54,10 & 15,00 & 23,81 & 69,84 & 56,67 \\
FDA (\% MS) & 31,59 & 6,78 & 17,54 & 56,67 & 47,14 \\
Lignina (\% MS) & 5,65 & 0,53 & 3,01 & 1,98 & 4,43 \\
Amido (\% MS) & 26,01 & 71,98 & 21,88 & 5,08 & 29,35 \\
EB (Mcal/kgMS) & 4,53 & 4,37 & 4,32 & 4,17 & 4,80
\end{tabular}

$\mathrm{MS}=$ matéria seca; $\mathrm{MO}=$ matéria orgânica; $\mathrm{PB}=$ proteína bruta; $\mathrm{FDN}=$ fibra em detergente neutro; $\mathrm{FDA}=$ fibra em detergente ácido; $\mathrm{EB}=$ energia bruta. 
Tabela II. Ingredientes e composição nutricional das dietas experimentais. (Ingredients and nutritional composition of experimental diets).

\begin{tabular}{lrrrr}
\hline & $\mathrm{MU}^{1}$ & \multicolumn{1}{c}{$\mathrm{PU}^{2}$} & $\mathrm{MFG}^{3}$ & $\mathrm{PFG}^{4}$ \\
Ingrediente (\%) & \multicolumn{5}{c}{ Composição } & percentual \\
\hline Silagem de milho & 40,00 & 40,00 & 40,00 & 40,00 \\
Grão de milho & 39,68 & 8,71 & 33,26 & 2,90 \\
Polpa cítrica & 4,97 & 44,80 & 2,92 & 34,20 \\
Casca de soja & 13,00 & 3,87 & 4,03 & 1,99 \\
Ureia & 1,40 & 1,68 & - & - \\
Farelo de girassol & - & - & 18,89 & 20,25 \\
Calcário calcítico & 0,28 & - & 0,32 & - \\
Sal & 0,57 & 0,58 & 0,57 & 0,57 \\
Fosfato bicálcico & - & 0,36 & - & - \\
& & & & \\
Nutriente (\%MS) & Composição nutricional \\
& & & & \\
PB & 13,23 & 12,74 & 13,32 & 12,91 \\
FDN & 39,79 & 39,04 & 43,28 & 46,81 \\
FDA & 25,63 & 25,29 & 28,64 & 31,53 \\
Lignina & 3,45 & 4,31 & 4,02 & 4,82 \\
Amido & 40,72 & 26,68 & 40,74 & 26,06 \\
EB (Mcal/kg) & 4,30 & 4,29 & 4,47 & 4,48 \\
\hline
\end{tabular}

${ }^{1}$ Dieta com alto teor de milho + ureia; ${ }^{2}$ Dieta com alto teor de polpa cítrica + ureia; ${ }^{3}$ Dieta com alto teor de milho + farelo de girassol; ${ }^{4}$ Dieta com alto teor de polpa cítrica + farelo de girassol.

$\mathrm{PB}=$ proteína bruta; $\mathrm{FDN}=$ fibra em detergente neutro; $F D A=$ fibra em detergente ácido; $E B=$ energia bruta.

animais, valores de 1 a 5 , de acordo com a escala: 1 (muito magro); 2 (magro); 3 (médio); 4 (gordo) e 5 (muito gordo), de acordo com metodologia adaptada de Edmonson et al. (1989).

Ao final dos 94 dias do período experimental, os animais foram abatidos em frigorífico comercial, e as medidas de peso da carcaça quente (PCQ) e peso da carcaça fria (PCF) foram obtidas para determinação de rendimentos de carcaça quente (RCQ) e fria (RCF) (Rocha Júnior et al., 2010). As carcaças foram resfriadas por 24 horas à $1^{\circ} \mathrm{C}$. $\mathrm{Na}$ desossa, as meias carcaças esquerdas foram separadas em dianteiro (pescoço, paleta, braço e cinco costelas), traseiro (região posterior separada do dianteiro entre a $5^{\mathrm{a}}$ e $6^{\mathrm{a}}$ costelas) e ponta de agulha (costelas a partir da $6^{\mathrm{a}}$ e músculos abdominais). Os pesos das peças foram convertidos em porcentagem em relação ao peso da carcaça fria (Müller, 1987). As meias carcaças direitas foram utilizadas para medir comprimento de carcaça, perna e braço, largura da carcaça e espessura de coxão. Também do lado direito, foi feito corte transversal entre a $12^{\mathrm{a}}$ e a $13^{\mathrm{a}}$ costelas expondo o músculo Longissimus thoracis, para avaliação da área de olho de lombo (AOL), com auxílio de régua quadriculada (ISU, 1989) e espessura de gordura subcutânea (EG), utilizando-se de paquímetro analógico.

Foi utilizado o delineamento inteiramente casualizado, com quatro tratamentos e seis repetições, sendo que cada animal foi considerado uma unidade experimental. Os dados foram submetidos à análise de variância e para a comparação de médias foi utilizado o teste $t$, adotando-se o nível de significância de $5 \%$. Todas as análises foram realizadas com o auxílio do programa estatístico SAS System (SAS, 1993).

\section{RESULTADOSEDISCUSSÃO}

As dietas experimentais influenciaram $(\mathrm{p}<0,05)$ o consumo de matéria seca (CMS) (tabela III). Os animais que consumiram as dietas com milho e ureia (MU), milho e farelo de girassol (MFG) e polpa cítrica e farelo de girassol (PFG) apresentaram CMS semelhantes $(\mathrm{p}>0,05)$. Já aqueles que consumiram a dieta com polpa cítrica e ureia (PU) apresentaram menores CMS $(p<0,05)$, expressos em $\mathrm{kg}$ ou em \%PV. Isso pode ter ocorrido devido a redução na palatabilidade do alimento promovido pela elevada concentração de polpa cítrica neste tratamento (45\%). Este resultado foi descrito por Henrique et al. (1998), Faturi et al. (2006) e Gonçalves (2010) em dietas para ruminantes contendo 60,70 e $80 \%$ de concentrado com 
Tabela III. Consumo diário de matéria seca (MS), proteina bruta $(P B)$ e fibra em detergente neutro (FDN), de acordo com as dietas experimentais. (Daily intakes of dry matter (MS), crude protein (PB) and neutral detergent fiber (FDN), according to experimental diets).

\begin{tabular}{lccccc}
\hline Consumo & MU & PU & MFG & PFG & CV (\%) \\
\hline MS (kg) & $10,65^{\mathrm{a}}$ & $8,30^{\mathrm{b}}$ & $10,87^{\mathrm{a}}$ & $10,52^{\mathrm{a}}$ & 13,66 \\
MS (\%PC) & $2,60^{\mathrm{a}}$ & $1,13^{\mathrm{b}}$ & $2,65^{\mathrm{a}}$ & $2,56^{\mathrm{a}}$ & 12,90 \\
PB (kg) & $1,42^{\mathrm{a}}$ & $1,03^{\mathrm{b}}$ & $1,4^{\mathrm{a}}$ & $1,33^{\mathrm{a}}$ & 14,73 \\
FDN $(\mathrm{kg})$ & $4,06^{\mathrm{b}}$ & $3,31^{\mathrm{c}}$ & $4,50^{\mathrm{ab}}$ & $4,93^{\mathrm{a}}$ & 13,64 \\
FDN $(\% P C)$ & $0,99^{\mathrm{bc}}$ & $0,85^{\mathrm{c}}$ & $1,10^{\mathrm{ab}}$ & $1,20^{\mathrm{a}}$ & 13,07 \\
\hline
\end{tabular}

abcMédias, na linha, seguidas por letras iguais, não diferem pelo teste $t$.

$\mathrm{MU}=$ Dieta com alto teor de milho + ureia; $\mathrm{PU}=$ Dieta com alto teor de polpa cítrica + ureia; $M F G=\mathrm{Dieta}$ com alto teor de milho + farelo de girassol; PFG= Dieta com alto teor de polpa cítrica + farelo de girassol.

elevadas concentrações de polpa cítrica. Da mesma forma, o consumo de proteína bruta (CPB) acompanhou o comportamento do CMS. Os menores CPB $(\mathrm{p}<0,05)$ foram observados em animais da dieta PU, e as demais dietas mostraram médias similares $(\mathrm{p}>0,05)$.

O mesmo comportamento, foi observado para o consumo de fibra em detergente neutro $(\mathrm{CFDN})$ em relação a dieta PU. Contudo, quando esta variável foi expressa em \%PC, nos tratamento PU e MU foram obtidos as menores médias $(p<0,05)$, embora o CFDN encontrado na dieta MU tenha sido semelhante $(p>0,05)$ ao CFDN da dieta MFG. Isso demonstrou que a associação de ingredientes energéticos com o farelo de girassol apresentaram maiores CFDN e confirmou os resultados de Mendes (2003) obtidos com dieta composta por milho, casca de soja e farelo de gérmen de milho associada ao farelo de girassol.

Os menores consumos de matéria seca e de proteína bruta apresentados pelos animais do tratamento PU proporcionaram ganho em peso médio diário (GPMD) de apenas $0,97 \mathrm{~kg}$, sendo este inferior $(\mathrm{p}<0,05)$ em $0,5 \mathrm{~kg} /$ dia aos valores obtidos nas demais dietas (tabela IV). Desta forma, a associação polpa cítrica e ureia não proporciona resultados satisfatórios para GPMD de bovinos.
O mesmo fato foi observado em trabalho com ovinos alimentados com esses ingredientes (Gonçalves, 2010).

A substituição de milho por polpa cítrica pode resultar em déficit energético, pois o milho possui maior concentração de amido ( 82 e $18 \%$ na matéria seca, respectivamente) e menor degradabilidade potencial e efetiva, quando comparado à polpa cítrica (Faturi, 2005). Porém, é possível obter resultados positivos em se substituir parcialmente ou totalmente o milho pela polpa cítrica em dietas para bovinos mestiços confinados (Prado et al., 2000), o que não ocorreu no presente trabalho.

As médias do escore corporal acompanharam o comportamento do GPMD em função das dietas e confirmam o efeito adverso da dieta PU. Por outro lado, a conversão alimentar da matéria seca e da proteína bruta não foram influenciadas $(p>0,05)$ pelas dietas experimentais.

Analisando os pesos de carcaça quente (PCQ) e fria (PCF) (tabela V), observou-se, em ambos os casos, que os menores valores $(p<0,05)$ foram verificados nos animais que consumiam a dieta $\mathrm{PU}$, sem diferença entre as demais dietas $(p>0,05)$. Este resultado mais uma vez foi consequência do menor GMPD e do menor peso ao abate destes animais (tabela IV). 
Tabela IV. Médias de peso corporal inicial e final, ganho em peso médio diário (GPMD), conversão alimentar (CA), conversão alimentar da proteína bruta (CAPB) e escore corporal $(E C)$, em função das dietas experimentais. (Initial and final body weight, average daily gain (GPMD), feed conversion (CA), feed conversion of crude protein (CAPB) and body score (EC), depending on the experimental diets).

\begin{tabular}{lccccc}
\hline Consumo & MU & PU & MFG & PFG & CV (\%) \\
\hline Peso corporal inicial (kg) & 324,77 & 325,71 & 328,57 & 329,94 & 2,35 \\
Peso corporal final (kg) & $468,91^{\mathrm{a}}$ & $430,88^{\mathrm{b}}$ & $470,19^{\mathrm{a}}$ & $471,02^{\mathrm{a}}$ & 2,98 \\
GPMD (kg) & $1,45^{\mathrm{a}}$ & $0,97^{\mathrm{b}}$ & $1,47^{\mathrm{a}}$ & $1,48^{\mathrm{a}}$ & 13,32 \\
CA (kg CMS/kg ganho) & 7,40 & 8,57 & 7,55 & 7,09 & 13,64 \\
CAPB (kg CPB/kg ganho) & 0,98 & 1,06 & 1,00 & 0,90 & 13,95 \\
EC $^{*}$ & $3,86^{\mathrm{a}}$ & $3,64^{\mathrm{b}}$ & $3,90^{\mathrm{a}}$ & $4,00^{\mathrm{a}}$ & 4,45 \\
\hline
\end{tabular}

abMédias, na linha, seguidas por letras iguais, não diferem pelo teste $t$.

$\mathrm{MU}=$ Dieta com alto teor de milho + ureia; $\mathrm{PU}=$ Dieta com alto teor de polpa cítrica + ureia; $\mathrm{MFG}=$ Dieta com alto teor de milho + farelo de girassol; $\mathrm{PFG}=$ Dieta com alto teor de polpa cítrica + farelo de girassol. *1= muito magro; 2= magro; $3=$ médio; 4= gordo; 5= muito gordo.

Os rendimentos de carcaça quente (RCQ) e fria (RCF) (tabela $\mathbf{V}$ ) dos animais que consumiram a dieta MU foram inferiores $(\mathrm{p}<0,05)$ àqueles observados nas dietas $\mathrm{PU}$ e MFG, porém semelhantes aos da dieta PFG. Neste último caso, os RCQ e RCF foram semelhantes $(p>0,05)$ aos verificados nos tratamentos PU e MFG.

Com exceção dos resultados observados na dieta MU, Henrique et al. (1998) encontraram valores de RCQ de tourinhos $(52,40 \%)$ semelhantes à média obtida no presente trabalho $(52,82 \%)$. Sabendo que os PCQ são relacionados com o peso corporal ao abate, verificou-se que mesmo tendo sido obtido um maior valor para esta variável no tratamento MU, o RCQ não acompanhou tal comportamento quando comparado aos dos demais tratamentos. Sabe-se que a carcaça é composta basicamente da porção muscular, dos ossos e da gordura. Dentre estes, a gordura é o componente mais variável que se relaciona diretamente com o rendimento de carcaça já que influencia no grau de acabamento desta o qual, por sua vez, é reflexo do tipo da dieta. Desta forma, supõe-se que as maiores proporções de carboidratos fibrosos (solúveis e insolúveis) cetogênicos das dieta PU, MFG e PFG oriundos, respectivamente, da polpa cítrica e do farelo de girassol ao serem fermentadas no rúmen à acetato (Hall, 2001), proporcionaram uma maior deposição de gordura na carcaça elevando os seus rendimentos. O contrário aconteceu nas carcaças dos animais da dieta MU que consumiram uma dieta rica em amido, carboidrato que por ser glicogênico não atuou diretamente na síntese de gordura da carcaça fazendo com que seu rendimento fosse reduzido. Quanto às características de desenvolvimento da carcaça como comprimento da carcaça, de perna, espessura de coxão e largura da carcaça (tabela V), observa-se que estas não foram influenciadas pelos tratamentos $(\mathrm{p}>0,05)$. A exceção se deu apenas para o comprimento do braço em que aquele observado nas carcaças dos animais do tratamento MFG foram semelhantes ( $p>0,05)$ apenas aos encontrados no tratamento $\mathrm{PFG}$, não sendo verificadas diferenças $(p>0,05)$ deste último quando comparado aos resultados dos demais tratamentos (MU- 37,28 e PU$37,45 \mathrm{~cm})$. Efeitos significativos $(\mathrm{p}<0,05)$ proporcionados pelas dietas experimentais também foram observados para o perímetro 
Tabela $\boldsymbol{V}$. Efeito das dietas experimentais sobre as características quantitativas das carcaças de novilhos em confinamento. (Effect of experimental diets on quantitative carcass traits of feedlot steers).

\begin{tabular}{|c|c|c|c|c|c|}
\hline Consumo & MU & PU & MFG & PFG & CV $(\%)$ \\
\hline $\mathrm{PCQ}(\mathrm{kg})$ & $238,90^{a}$ & $226,73^{b}$ & $247,51^{\mathrm{a}}$ & $237,94^{a}$ & 4,97 \\
\hline $\mathrm{RCQ}(\%)$ & $50,69^{c}$ & $52,35^{\mathrm{ab}}$ & $52,44^{a b}$ & $51,80^{\mathrm{bc}}$ & 2,17 \\
\hline $\mathrm{PCF}(\mathrm{kg})$ & $238,37^{a}$ & $226,55^{b}$ & $247,26^{a}$ & $237,14^{a}$ & 5,12 \\
\hline RCF $(\%)$ & $50,57^{c}$ & $52,30^{\mathrm{ab}}$ & $52,38^{\mathrm{ab}}$ & $51,63^{\mathrm{bc}}$ & 2,35 \\
\hline Comprimento da carcaça $(\mathrm{cm})$ & 127,50 & 124,16 & 125,75 & 126,87 & 2,23 \\
\hline Largura $(\mathrm{cm})$ & 38,70 & 38,73 & 38,97 & 37,37 & 3,91 \\
\hline Espessura de coxão (cm) & 27,39 & 25,95 & 27,11 & 26,74 & 5,53 \\
\hline Comprimento de perna (cm) & 73,70 & 74,16 & 76,20 & 71,97 & 3,51 \\
\hline Comprimento de braço $(\mathrm{cm})$ & $37,28^{\mathrm{ab}}$ & $37,45^{\mathrm{ab}}$ & $38,76^{c}$ & $38,26^{\mathrm{bc}}$ & 2,31 \\
\hline Perímetro de braço $(\mathrm{cm})$ & $37,36^{a}$ & $35,55^{\mathrm{b}}$ & $38,64^{a}$ & $37,34^{a}$ & 3,04 \\
\hline Área de olho de lombo $\left(\mathrm{cm}^{2}\right)$ & 62,01 & 68,03 & 68,95 & 63,99 & 9,29 \\
\hline Espessura de gordura (mm) & $4,52^{\mathrm{a}}$ & $4,66^{a}$ & $4,81^{a}$ & $2,79^{b}$ & 22,76 \\
\hline Traseiro (\%) & 46,90 & 47,07 & 46,99 & 47,01 & 2,75 \\
\hline Dianteiro $(\%)$ & 37,71 & 38,66 & 38,27 & 38,32 & 2,86 \\
\hline Ponta de agulha (\%) & 15,38 & 14,26 & 14,74 & 14,66 & 5,12 \\
\hline
\end{tabular}

abcMédias, na linha, seguidas por letras iguais, não diferem pelo teste $t$ a $5 \%$ de significância. MU: Dieta com alto teor de milho + ureia; PU: Dieta com alto teor de polpa cítrica + ureia; MFG: Dieta com alto teor de milho + farelo de girassol; PFG: Dieta com alto teor de polpa cítrica + farelo de girassol. $\mathrm{PCQ}=$ peso da carcaça quente; $\mathrm{RCQ}=$ rendimento de carcaça quente; $\mathrm{PCF}=$ peso da carcaça fria; $\mathrm{RCF}=$ rendimento de carcaça fria.

de braço onde o menor valor foi obtido para os animais do tratamento PU, não havendo diferenças significativas $(\mathrm{p}>0,05)$ entre os demais $(37,78 \mathrm{~cm}$, em média), indicando que os animais que receberam polpa cítrica e ureia apresentaram menor desenvolvimento muscular que os demais, corroborando com seu peso corporal final. Avaliando a mesma característica, Restle et al. (2000) observaram valor inferior $(34,5 \mathrm{~cm})$ aos obtidos nesse experimento, abatendo animais com média de peso corporal de $425 \mathrm{~kg}$, semelhante ao apresentado pelos animais da dieta PU $(430,9 \mathrm{~kg})$.

Para área de olho de lombo (tabela V), que representa uma característica relacionada com a composição da carcaça e o rendimento de cortes cárneos de alto valor comercial, refletindo a maturidade fisiológica, não foram encontradas diferenças significativas $(\mathrm{p}>0,05)$.
Não houve variação ( $p>0,05)$ nos valores de espessura de gordura (tabela $\mathbf{V})$ entre os animais dos tratamentos MU, PU e MFG $(4,66 \mathrm{~mm})$. A exceção foi verificada para o tratamento PFG no qual foi obtido o valor de $2,79 \mathrm{~mm}$, sendo este inferior $(\mathrm{p}<0,05)$ aos demais. Segundo Luchiari Filho (2000), o valor de $3 \mathrm{~mm}$ seria considerado o mínimo de espessura de gordura necessário para assegurar a qualidade da carne, valor este que não foi alcançado no tratamento PFG. Esta inadequada cobertura de gordura observada nos animais deste tratamento pode deixar a carne mais susceptível ao encurtamento das fibras musculares durante o resfriamento (cold-shortening), fator este que implica diretamente na ausência de maciez da carne (Lawrie, 2004).

É possível que a presença de polpa cítrica tenha, pelo menos em parte, afetado de as vias de deposição de gordura, redirecio- 


\section{VAN CLEEF, EZEQUIEL, GONÇALVES, FONTES, OLIVEIRA E STIAQUE}

nando-a para outros sítios que não a gordura de cobertura quando este ingrediente esteve associado ao farelo de girassol.

Quanto às porcentagens dos cortes comerciais (tabela V) não houve diferenças $(\mathrm{p}>0,05)$ em função dos tratamentos sendo observados valores médios de $46,99 \%$ para o traseiro, $38,24 \%$ para o dianteiro e $14,76 \%$ para a ponta de agulha (Peron et al., 1993).

\section{BIBLIOGRAFIA}

ANUALPEC. 2011. Anuário da Pecuária Brasileira FNP Consultoria. São Paulo. 376 pp.

AOAC. 1995. Association of Official Agricultural Chemists. Official methods of analysis of AOAC. $16^{\mathrm{a}}$ ed. AOAC International. Arlington.

Carvalho, M.P. 1995. Citrus. Em: Simpósio sobre nutrição de bovinos. Utilização de resíduos culturais e benefeciamento na alimentação de bovinos. Anais... Fundação de Estudos Agrários Luiz de Queiroz. Piracicaba, SP. pp. 171-214.

Cooper, R.J., Milton, C.T., Klopfenstein, T.J. and Jordon, D.J. 2002. Effect of corn processing on degradable intake protein requirement of finishing cattle. J Anim Sci, 80: 242-247.

Edmonson, A.J., Lean, I.J., Weaver, L.D., Farver T. and Webster, G. 1989. A body condition scoring chart for Holstein dairy cows. J Dairy Sci, 72: 68-78.

Faturi, C. 2005. Fontes de carboidratos solúveis e níveis de fibra em detergente neutro em dietas para terminação de novilhos em confinamento. Tese (Doutorado em Zootecnia). FCAV, UNESP. Jaboticabal, SP. 73 pp.

Faturi, C., Ezequiel, J.M.B., Fontes, N.A., Stiaque, M.G. e Silva, O.G.C. 2006. Fibra solúvel e amido como fontes de carboidratos para terminação de novilhos em confinamento. Rev Soc Bras Zootecn, 35: 2110-2117.

Ferreira, M.A., Valadares Filho, S.C., Coelho da Silva, J.F., Paulino, M.F., Valadares, R.F.D. e Cecon, P.R. 1999. Consumo, conversão alimentar, ganho de peso e características da carcaça de bovinos F1 Simental x Nelore. Rev Bras Zootecn, 28: 343-351.

Galati, R.L. 2004. Co-produtos do milho, soja e girassol em dietas para bovinos de corte. Tese (Doutorado em Zootecnia). Universidade

\section{CONCLUSÕES}

A dieta com polpa cítrica e ureia, quando a polpa cítrica substituir parcialmente ou totalmente o milho, como fonte energética, determina efeitos negativos no desempenho animal e em algumas características de carcaça, possivelmente em decorrência de um possível desequilíbrio energético.

Estadual Paulista. Jaboticabal, SP. 168 pp.

Gonçalves, J.S. 2010. Amido e fibra solúvel em detergente neutro em dietas para ovinos. Tese (Doutorado em Zootecnia). FCAV, UNESP. Jaboticabal, SP.

Haliburton, J.C. and Morgan, S.E. 1989. Nonprotein nitrogen-induced ammonia toxicosis and ammoniated feed toxicity syndrome. Vet Clin North Am Food Anim Pract, 5: 237-249.

Hall, M.B. 2001. Recent advanced in non-NDF carbohydrates for the nutrition of lactating cows, Em: Simpósio Internacional em Bovinos de Leite. Anais... UFLA-FAEPE. Lavras. pp. 139-148.

Henrique, W., Leme, P.R., Lanna, D.P.D., Coutinho Filho, J.L.V., Peres, R.M., Justo, C.L., Siqueira, P.A. e Alleoni, G.F. 1998. Substituição de amido por pectina em dietas com diferentes níveis de concentrado. 1. Desempenho animal e características da carcaça. Rev Bras Zootecn, 27: 1206-1211.

Ipharraguerre, I.R. and Clark, J.H. 2003. Soyhulls as an alternative feed for lactating cows: A review. J Dairy Sci, 86: 1052-1073.

ISU. 1989. lowa State University (ISU). Plastic grid for quick measurement of loin eye (Beef). lowa State University. AS-234.

Kertz, A.F. 2010. Urea feeding to dairy cattle: A historical perspective and review. Prof Anim Sci, 26: 257-272.

Lawrie, R.A. 2004. Ciência da carne. $6^{\text {a }}$ ed. Artmed. Porto Alegre. $384 \mathrm{pp}$.

Lema, A.C.F. 2001. Produção e qualidade de carcaças de bovinos terminados em confinamento. 2001. Tese (Doutorado em Zootecnia). FCAV, UNESP. Jaboticabal. 95 pp.

Luchiari Filho, A. 2000. Pecuária da carne bovina. LinBife. São Paulo, 134 pp.

Archivos de zootecnia vol. 61, núm.235, p. 422. 


\section{NOVILHOS CONFINADOS COM FONTES DE PROTEÍNA E ENERGIA}

Mendes, A.R. 2003. Fontes energéticas associadas ao farelo de girassol em dietas para bovinos em confinamento. Tese (Doutorado em Zootecnia). Faculdade de Ciências Agrárias e Veterinárias. Universidade Estadual Paulista. Jaboticabal. 103 pp.

Müller, L. 1987. Normas para avaliação de carcaças e concurso de carcaças de novilhos. $2^{\mathrm{a}}$ ed. Departamento de Zootecnia. Santa Maria. 30 pp.

NRC. 1984. National Research Council. Nutrient requeriments of beef cattle. $6^{a}$ ed. National Academy Press. Washington, D.C. 50 pp.

NRC. 1996. National Research Council. Nutrient requirements of beef cattle. $7^{\mathrm{a}} \mathrm{ed}$. Academy Press. Washington. 242 pp.

Peron, A.J., Fontes, C.A.A., Lana, R.P., Paulino, M.F., Queiroz, A.C. e Freitas, J.A. 1993 Rendimento de carcaça e de seus cortes básicos e área corporal de bovinos de cinco grupos genéticos, submetidos a alimentação restrita e ad libitum. Rev Soc Bras Zootecn, 22: 238-247.

Prado, I.N., Pinheiro, A.D., Alcalde, C.R., Zeoula, L.M., Nascimento, W.G. e Souza, N.E. 2000. Níveis de substituição do milho pela polpa de citros peletizada sobre o desempenho e características de carcaça de bovinos mestiços con- finados. Rev Bras Zootecn, 29: 2135-2141.

Restle, J., Vaz, F.N., Feijó, G.L.D., Brondani, I.L., Alves Filho, D.C., Bernardes, R.A.C., Faturi, C. e Pacheco, P.S. 2000. Características de carcaça de bovinos de corte inteiros ou castrados de diferentes composições raciais Charolês $x$ Nelore. Rev Bras Zootecn, 29: 1371-1379.

Rocha Júnior, V.R., Silva, F.V.E., Barros, R.C., Reis, S.T., Costa, M.D., Souza, A.S., Caldeira, L.A., Oliveira, T.S. e Oliveira, L.L.S. 2010. Desempenho e características de carcaça de bovinos Nelore e Mestiços terminados em confinamento. Rev Bras Saúde Prod An, 11: 865-875.

Santos, F.A.P., Pereira, E.M. e Pedroso, A.M. 2004. Suplementação energética de bovinos de corte em confinamento. Em: Simpósio sobre Bovinocultura de Corte. Anais... Fundação de Estudos Agrários "Luiz de Queiroz". PiracaibaSP. pp. 261-297.

SAS. 1993. SAS INSTITUTE.SAS/STAT User's guide: statistics. $4^{a}$ ed. Version 6. Cary, NC. 943 pp.

Silva, D.J. e Queiroz, A.C. 2005. Análise de alimentos: métodos químicos e biológicos. $3^{\mathrm{a}}$ ed. $2^{\mathrm{a}}$ Reimpressão. UFV. Viçosa. 235 pp. 